\title{
PREFACE
}

In the very early stages of this research, I planned to do a comparative study of Berkeley and other institutions. But the ambition quickly withered for lack of a common theoretical perspective and proper kinds of comparative data. I decided then to do a case study concentrating on Berkeley (but taking into account the other University of California campuses) - a project designed to raise hypotheses and generate new theory, rather than verify existing theory.

Despite the extensive literature on authority, a subject that is central to much of the sociology of politics and organizations, there is relatively little empirically grounded discussion of university authority. What does exist was not always useful. A common approach in these studies would be an application of Weber's notion of bureaucracy to university administration. Yet such a simple superimposition of a legal-rational model onto the university scene ignores the enormous gap between the almost anarchic style of most college administrations and the rigid structure of the typical business bureaucracy. Furthermore, there have been few attempts to systematically categorize the shifting patterns of authority over students. 
The task, as I see it, is to set up a model of university governance which will combine existing theory with the unique qualities of educational institutions. At the same time, the model must comprise a historical perspective that will clarify the transition from paternalism to formal control, from relative placidity to present-day rebellion. And finally, the conceptualization should suggest alternative courses of action that might determine future developments as well as some tentative predictions.

Although research stages are usually mixed and not consecutive, the work has proceeded in a manner which can be broken down into three stages: preliminary conceptualization, data collection and the construction of substantive categories, and reduction of categories. The third stage also includes an attempt to encompass past trends and present tensions in a more general theory capable of shedding some light on the bureaucratic trends of modern society.

\section{Preliminary Conceptualization}

This first stage comprises development of a preliminary formulation of the concept of authority. The breakdown of this concept into tangible dimensions has enabled me to isolate the phenomenon. Since everything is related to everything else, without some limitation on the scope of the concept, the task would have been endless-and meaningless. For example, if authority had been broadly defined as control-instead of as power justified by beliefs held in common by subordinates and superordinates-then collection of extensive data on the public pressures on the university would have been required. Research would have had to include an analysis of legislative control, of informal pressure groups, and many other factors. However, given this alternative definition of authority, I have been able to ignore problems of public pressure except insofar as they explicitly impinge on relations between students and the authorities.

Furthermore, the quite general formulation of the various concepts has allowed me to tie the research into existing theory, which has then provided further clues for understanding the phenomena under study. Durkheim's concept of "mechanical solidarity" is rich with suggestions for comprehending the essence of paternalism. So too, Weber's category of legal-rational authority provides many clues for understanding the internal tensions of contemporary university authority. Needless to say, this constant interplay between the general concepts and the specif- 
ics of history has been most useful in putting facts into some kind of order and in developing ideas.

Finally, the specification of categories within a general framework of existing theory has allowed me to move toward formal theory that might have application to organizations other than universities.

\section{Data Collection and the}

\section{Construction of Substantive Categories}

The second phase of the project has been concerned with uncovering the actual historical events and developing substantive categories out of them. This work has not simply consisted of collecting data and coding it for preconceived categories, but has involved the reconstruction of the university's past in a way that would encourage development of substantive categories capturing the unique pattern and style of a specific period. It was at this stage that the general concept of authority was broken down into types such as authoritarian paternalism and paternalistic bureaucracy.

Unfortunately, I was well into the laborious process of data collection before discovering the relatively efficient method of category construction provided by focusing on crises. As long as administrative actions concerned mainly routine matters, they were widely accepted by the students and there was little discussion of the principles, the scope, or the concrete operations of authority. It was in the nonroutine matters-that is, in a crisis - that its authority was challenged, its workings revealed. A single case, such as the expulsion of a student for the "mere existence of a court record," could tell far more about authority than any cross-sectional survey of student opinion on the subject. Even were such ex post facto surveys possible, they would not necessarily have exposed the principles, the lack of appeal procedures, the focus of power, nor the arbitrary nature of authority. A crisis typically reveals the structure of authority by forcing the administration to defend its actions. In a real sense, arguments over specific actions performed the job of research.

Once having exposed the operations of the system, it is then possible to construct and label the substantive categories by comparing their properties-principles, scope, and structures-over a period of time. There would be a comparison, say, of character-building with narrower definitions of educational function, or a contrast between the "not too friendly chat" of old and the later implementation of elaborate procedures of due process. 
This "constant comparative method"-moving easily from data to categories and back again, and from one time period to another-produces a classification out of the data itself and not from an arbitrary superimposition from the lofty reaches of grand theory. ${ }^{1}$ Hopefully, this kind of category construction provides a link between concrete historical events and the more abstract categories such as mechanical solidarity or legal-rational authority.

Still, it might be asked, how valid are the substantive categories? How do we know, for example, that the category we have called "paternalistic self-government," which has only been arrived at through an abstract reconstruction of past events, is an adequate formulation of this pattern of authority? Obviously, we cannot survey a student body long since graduated to test their loyalty, nor can we interview the dead or the very old. Yet there is some ground for confidence in a formulation where such a close connection exists between substantive categories and data. To a large degree, the categories grew out of the continual historical comparison, and thus were the product of inductive analysisany preliminary notions of authority only serving as rough classifications for coding the data into principles, scope, etc. The variety of sources also lends credence to the categories. When different views of the same event either support or else do not contradict one another, then confidence about the nature of the events is well based. This does not mean that the witnesses necessarily interpreted the action in the same way, but rather that they agreed on the basic facts. For example, all the relevant observations about one period during the regime of President Wheeler points to the intense solidarity characteristic of the time. Not all agreed on the value of solidarity, but all agreed it was there. To Vern Smith it may have been coercive, to others it meant cooperative harmony, but all thought solidarity existed. By compiling observations from a variety of sources, confidence is built concerning one's understanding of the true nature of the period.

There is, finally, the attainment of a "theoretical saturation," and this, too, supports the belief that one's research is on the right track. ${ }^{2}$ Whereas in early stages of category development each new source of data adds another aspect to the conceptualization, after a period of

\footnotetext{
${ }^{1}$ Barney Glaser, The Discovery of Grounded Theory: Strategies for Qualitative Research (Chicago: Aldine Publishing Co., 1967). See especially Chapter 5. My methodological explanation owes much to Glaser's work.

${ }^{2}$ Glaser, p. 61.
} 
time, no matter how varied the sources, the data neither contradict nor add anything new to the conceptualization. To make a clarifying analogy, a piece of sculpture begins with a block of stone. A few chips here and there produces an outline that, however rough, unmistakably resembles a human face. A few more chips bring out distinct features and finally one is able to fully identify a particular person. This point is akin to our theoretical saturation with data. More work might be done to further refine the sculpture, but a distinct identity-if that is the aimhas already been achieved. Somewhere there may exist a vast cache of data the implications of which would radically alter both categories and conclusion. But such seems unlikely to one who, having already compared data from many diverse perspectives, has found nothing to contradict the present conclusions.

The problem of data collection and conceptualization became a great deal easier for the period after 1934 and the advent of written rules. After all, written rules are by their very nature explicit, public, and open to debate, thus allowing the researcher to focus immediately on the central elements of government. To say, however, that rules are a point of entry into the core of a complicated system is not to suggest they are taken at face value, but simply that they function as a starting point for analysis. ${ }^{3}$

Rules, based as they are upon some community consensus, reflect the nature of the community, its aims and its governing principles. If there is conflict within the community, such conflict is clearly reflected in the rules. Written regulations are also useful devices for understanding the position of the university in relation to the larger society, for they are often written in response to public relations crises and then used to justify retroactively specific administrative actions that had been criticized by either the students or the public. In short, written rules make the pattern of authority, and the challenges to it, more explicit and open.

Finally, a few words are in order on the data itself. In any historical study that is fundamentally exploratory, all available data is useful. At the start of research, data collection was directed toward a rough reconstruction of the major events of university history. Since no carefully researched histories of the university existed, one learned to make do with the typically nostalgic narratives published for the alumni. These were found useful-however embellished they were with institutional glorifi-

${ }^{3}$ I am grateful to Philip Selznick for bringing to my attention the crucial significance of written rules. 
cation-for their frequent references to certain outstanding events. Another source were student periodicals-the newspaper, the literary magazines, the humor publications, the multitude of short-lived journals, and even the political leaflets. These publications helped me in building up a chronology of events and indirectly contributed to the story by developing what is essential in the researcher, an intuitive feeling for the times. In the 1920s the student newspaper dropped its coverage of strictly campus affairs and turned to national and international news. Again, in the late 1930s, the campus humor magazine briefly turned away from its thirty-year-old jokes about sex to politics. Noticing such seemingly trivial changes led to impressions which were at times later verified by more substantial documentation.

But it was the first, fresh reading of a volume of student publications that always provided immensely rich and rewarding insights. Students are peculiarly sensitive barometers of the times. They are informed enough to know what is going on, but are often naive enough-or is it bold enough-to present things just as they see them. Of particular interest are the dissenting publications. In the nineteenth century there was an avowedly antifraternity paper; in the 1920 s, self-consciously sophisticated literary journals; and beginning in the $1930 \mathrm{~s}$, a huge number of radical periodicals. These outsiders served useful functions as "informers" on the system. The metropolitan press has been less valuable than one might expect and has been used primarily as an indicator of the university's relations with the larger community. Frankly, until the last few years, newspaper reporters did not seem to know much, or care much, about campus affairs. Personal letters, biographies, and memoirs certainly provide some insight into the subjective attitudes of participants, but they do little to help one reconstruct the total context of past events. Still, using all possible sources of information, it has been possible to place the official documents forming the hard core of the analysis into a larger perspective. Bland-sounding official reports indeed come alive when placed within a historical setting. Even more useful were the occasional court records covering the cases of expelled students which laid bare the actual university governance proceedings unencumbered by the moralistic trappings of institutional loyalty.

For the era after the 1930s, the presidential files become the most important source of data, since they contain the memos, letters, and legal opinions that have gone into the construction of the regulations. The comparisons of these private documents with the related public pro- 
nouncements, in addition to the juxtaposition of successive regulations and modifications against the changing pattern of the times, becomes a valuable foundation for later analysis.

Of course, no single source of data has made the whole story. Rather, the reconstruction and interpretation of events has been built on the constant comparison and checking back and forth among all sources of data. By this method, even apparently trivial pieces of informationsuch as the existence of a bench on which no one ever sits-take on great significance.

\section{Reduction of Categories}

The final stage of analysis consists in returning to the general concept of authority which is now enriched with the concrete facts of history and the substantive categories. In the concluding chapter, the aim is to move beyond the specific experience of Berkeley and, however tentatively, reach toward a more formal theory of university governance and organizational authority. The method of extending theory and generating new hypotheses is achieved for the most part by reducing the substantive categories to a few manageable variables and then proceeding to deductive speculations. For paternalism the organizing principle was loyalty and for legal-rational authority, the self-contained, rationally consistent cosmos of rules.

The abstract models serve several functions. They have been used to organize a myriad of events into consistent patterns, to clarify contemporary crises, and to specify possible outcomes. For example, the decline of solidarity meant the end of paternalism, while the emergence of a legal-rational system brought with it not only new methods of control but also the seeds of its own transformation. All such interpretations and tentative predictions can be more clearly presented through the use of simplified models, which in turn help the researcher make stronger assertions about particular cases.

The models also serve to promote the case study to a higher level of abstraction, thus allowing wider applicability. Rather than simply analyzing the specific regulations of university governance, it has been possible to work on the form of legal-rational authority. A case study of Berkeley can then suggest some inherent problems as well as potential changes in the bureaucratic form of organizational authority. No pretense to proof is asserted here but only a tentative hypothesis. To go beyond the case study would require a comparative analysis which would 
help clarify, prove, or disprove the substantive ideas about universities and the more formal theory about legal-rational authority. Although this particular study is circumscribed by the limitations of the case study approach, hopefully the findings combined with tentative gropings toward a more formal theory will cast some light on two critical issues of modern society - the crisis of university authority and the difficulties of individual freedom in the organizational society. 